\title{
Lissencephaly with cerebellar hypoplasia type F
}

INSERM

\section{Source}

INSERM. (1999). Orphanet: an online rare disease and orphan drug data base.

Lissencephaly with cerebellar hypoplasia type F. ORPHA:100016

Lissencephaly with cerebellar hypoplasia type $F(\mathrm{LCHf})$ is a severe form of lissencephaly with cerebellar hypoplasia, characterized by a microcephaly of at least - 3 SD and a thick cortex associated with complete absence of the corpus callosum. 